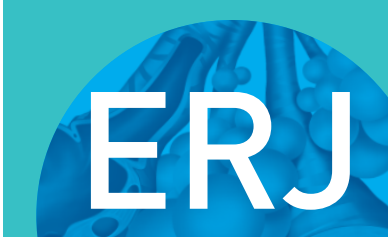

open research

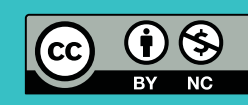

\section{Respiratory impedance measured using impulse oscillometry in a healthy urban population}

\author{
Kenneth I. Berger ${ }^{1,2}$, Margaret Wohlleber ${ }^{1,2}$, Roberta M. Goldring ${ }^{1,2}$, \\ Joan Reibman ${ }^{1,3}$, Mark R. Farfel ${ }^{4}$, Stephen M. Friedman ${ }^{4}$, Beno W. Oppenheimer ${ }^{1,2}$, \\ Steven D. Stellman ${ }^{4,5}$, James E. Cone ${ }^{4}$ and Yongzhao Shao ${ }^{6}$
}

Affiliations: ${ }^{1}$ Dept of Medicine, NYU Grossman School of Medicine, New York, NY, USA. ${ }^{2}$ André Cournand Pulmonary Physiology Laboratory, Bellevue Hospital, New York, NY, USA. ${ }^{3}$ Dept of Environmental Medicine, NYU Grossman School of Medicine, New York, NY, USA. "World Trade Center Health Registry, New York City Department of Health and Mental Hygiene, New York, NY, USA. ${ }^{5}$ Mailman School of Public Health, Columbia University, New York, NY, USA. 'Dept of Population Health, NYU Grossman School of Medicine, New York, NY, USA

Correspondence: Kenneth I. Berger, New York University School of Medicine, 240 East 38th Street, Room M-15, New York, NY 10016, USA. E-mail: kenneth.bergeranyumc.org

ABSTRACT This study derives normative prediction equations for respiratory impedance in a healthy asymptomatic urban population using an impulse oscillation system (IOS). In addition, this study uses body mass index (BMI) in the equations to describe the effect of obesity on respiratory impedance.

Data from an urban population comprising 472 healthy asymptomatic subjects that resided or worked in lower Manhattan, New York City were retrospectively analysed. This population was the control group from a previously completed case-control study of the health effects of exposure to World Trade Center dust. Since all subjects underwent spirometry and oscillometry, these previously collected data allowed a unique opportunity to derive normative prediction equations for oscillometry in an urban, lifetime nonsmoking, asymptomatic population without underlying respiratory disease.

Normative prediction equations for men and women were successfully developed for a broad range of respiratory oscillometry variables with narrow confidence bands. Models that used BMI as an independent predictor of oscillometry variables (in addition to age and height) demonstrated equivalent or better fit when compared with models that used weight. With increasing BMI, resistance and reactance increased compatible with lung and airway compression from mass loading.

This study represents the largest cohort of healthy urban subjects assessed with an IOS device. Normative prediction equations were derived that should facilitate application of IOS in the clinical setting. In addition, the data suggest that modelling of lung function may be best performed using height and BMI as independent variables rather than the traditional approach of using height and weight.

@ERSpublications

Prediction equations for respiratory impedance were derived in an urban cohort incorporating the effects of mass loading from obesity. Urban exposures had minimal effect on impedance allowing application of the equations to a broad range of populations. https://bit.ly/3a3zZvd

Cite this article as: Berger KI, Wohlleber M, Goldring RM, et al. Respiratory impedance measured using impulse oscillometry in a healthy urban population. ERJ Open Res 2021; 7: 00560-2020 [https://doi.org/10.1183/23120541.00560-2020].

This article has supplementary material available from openres.ersjournals.com

Received: 27 Aug 2020 | Accepted: 2 Dec 2020

Copyright $\odot$ ERS 2021. This article is open access and distributed under the terms of the Creative Commons Attribution Non-Commercial Licence 4.0. 


\section{Introduction}

Respiratory oscillometry is increasingly used to evaluate respiratory symptoms and augment the diagnostic capabilities of standard lung function assessments (e.g. spirometry and plethysmography) [1-3]. Respiratory oscillometry measures identify functional abnormalities in symptomatic subjects despite normal airflow by spirometry and have been shown to correlate with clinical symptoms, quality of life and response to therapy in subjects with established disease [4-6]. However, the routine use of oscillometry in the clinical setting has been limited by several factors, including a relative paucity of normative data derived using commercially available oscillometry systems.

Table 1 summarises selected spirometry normative data populations and published normative respiratory oscillometry data obtained using the impulse oscillation system (IOS). Normative equations for spirometry parameters have now been derived in large multiethnic populations [7-9]. In contrast, normative equations for IOS parameters are limited to studies of small population size, many with narrow age range and/or rural populations [10-13]. In addition, one multicenter study used variable equipment [14] and demonstrated that measured impedance data may differ considerably by device [14-17].

Traditionally, studies that derive equations to predict normative values for lung function include a variety of independent parameters to account for variability in lung size and lung mechanics in healthy individuals. The effects of excess body weight are particularly relevant for respiratory oscillometry testing since mass loading (i.e. excess body weight) alters respiratory impedance by reducing chest wall compliance with consequent lung and airway compression [18-23]. Thus, studies that assess normative values for respiratory oscillometry have generally included height and weight as independent predictors of impedance. However, this approach contrasts with clinical assessments that use BMI, which assesses the proportionality of weight to height within a subject. Moreover, prior data suggest that respiratory impedance measures may not vary in a linear manner with respect to body size and are likely magnified as BMI increases [19, 24].

We capitalised on an available dataset obtained in a large population of healthy adults that reside in an urban environment to derive normative prediction equations for respiratory impedance using the IOS device. In addition, we identified age, height and BMI as predictors and used BMI to describe the effect of obesity on respiratory impedance.

\section{Methods}

\section{Study participants}

Data from an urban population comprising 472 healthy asymptomatic subjects that resided or worked in lower Manhattan, New York City, NY, USA, were retrospectively analysed. This population was the control group from a previously completed case-control study of the health effects of exposure to World Trade Center (WTC) dust [25]. Since all subjects underwent spirometry and oscillometry in addition to longitudinal assessment of cardio-respiratory symptoms, diagnoses and treatments, these previously collected data provided a unique opportunity to derive normative prediction equations for IOS parameters in a healthy urban population. All subjects were adult enrollees in the WTC Health Registry of the New York City Department of Health and Mental Hygiene (nyc.gov/911health). Although all subjects were exposed to WTC dust, only healthy asymptomatic adults were included. Detailed medical history was obtained and inclusion criteria required that: 1) there was no prior history of respiratory disease or use of

TABLE 1 Summary of spirometry and impulse oscillation system (IOS) normative data publications

First author [ref.] Study summary

$\begin{array}{ll}\begin{array}{l}\text { Spirometry } \\ \text { KNUDSON [7] }\end{array} & \text { 697 individuals, age 6-85 years } \\ \text { HANKINSON [8] } & \text { USA population, 7429 individuals, age 8-80 years } \\ \text { QUANJER [9] } & 72 \text { centres, } 33 \text { countries, 74187 individuals, age 3-95 years } \\ \text { IOS } & \\ \text { SHIOTA [10] } & \text { Japanese population, } 166 \text { individuals, age 20-81 years } \\ \text { NEWBURY [11] } & \text { Australian population, 132 individuals, age 25-74 years } \\ \text { AARLI [12] } & \text { Norwegian population, 75 individuals, age 70-98 years } \\ \text { SCHULz [13] } & \text { German population, 397 individuals, age 45-91 years } \\ \text { OOSTVEEN [14] } & \text { Multiple European/Australian cities, 368 individuals, age 18-84 years, variable } \\ & \text { oscillometry devices used, IOS used in only } 62 \text { subjects }\end{array}$


respiratory medications or inhalers; 2) respiratory symptoms were absent on surveys and studies conducted on three separate occasions over 7 years (2003-2010); and 3) all subjects were lifetime nonsmokers $(<5$ packs per lifetime) $[25,26]$.

The initial case-control study and the present study were approved by the institutional review boards of the New York City Department of Health and Mental Hygiene and New York University.

\section{Lung function measurement}

Spirometry was performed according to published standards using the Jaeger Masterscreen system ( Jaeger, Yorba Linda, CA, USA) [27, 28]. Data included forced vital capacity and forced expiratory volume in $1 \mathrm{~s}$ $\left(\mathrm{FEV}_{1}\right)$. Results were classified into normal or abnormal patterns for each patient using their race/ethnicity and published lower limits of normal $[8,29]$.

Respiratory oscillometry was performed using the Jaeger Impulse Oscillation System (IOS, Jaeger) in accordance with published recommendations [30, 31]. Manoeuvres were performed during tidal breathing in the seated position, with a nose clip in place and with support of the cheeks. A minimum of three trials, each lasting $30 \mathrm{~s}$, were performed. The volume versus time tracings were analysed and only data from trials with nearly constant tidal volume and end-expiratory volume were analysed; this was confirmed by post hoc visual review of the volume versus time tracings. The volume versus time tracings were also inspected to ensure that there were no pauses suggestive of glottis closure and that there was no leak around the mouthpiece. Based on these criteria, the final cohort consisted of 439 individuals. Oscillometry parameters included: 1) resistance at oscillation frequencies of 5, 10, 15 and $20 \mathrm{~Hz}\left(R_{5}, R_{10}\right.$, $R_{15}$ and $R_{20}$, respectively); 2) frequency dependence of resistance calculated as the difference between $R_{5}$ and $R_{15}\left(R_{5-15}\right)$ and as the difference between $R_{5}$ and $\left.R_{20}\left(R_{5-20}\right) ; 3\right)$ reactance at 5 and $10 \mathrm{~Hz}\left(X_{5}\right.$ and $X_{10}$, respectively); 4) resonant frequency $\left(f_{\text {res }}\right)$; and 5) reactance area (AX) calculated as the area above the reactance curve from $5 \mathrm{~Hz}$ to $f_{\text {res. }}$. Reproducibility of $R_{5}$ between trials (coefficient of variation $<10 \%$ ) was required and average values for all oscillometry parameters were derived for each subject.

\section{Statistical analysis}

Separate multivariable analyses were performed to derive normative prediction equations for respiratory impedance in male and female subjects. The effect of race on prediction equations was not statistically significant so global equations were derived for each sex. Since the data were not normally distributed in this population, the prediction equations were derived for natural log IOS parameters (i.e. $\log$ transformation). An additional transformation was required for parameters with negative values as follows: 1) for $X_{5}$, a value of 4 was added to the measured value to ensure that there were no negative values prior to natural $\log$ transformation; 2) similarly, a value of 1 was added to the $R_{5-20}$ and $R_{5-15}$ prior to natural $\log$ transformation.

To account for body size, separate models were analysed using either weight or BMI, in addition to height and age, as independent predictors of respiratory function. Models that used age, height and/or weight squared did not result in improved fit. Thus, the final models selected were based on: 1) age, height and weight; and 2) age, height and BMI. To facilitate evaluation of the effects of obesity on respiratory impedance, the models presented were based on BMI. Mean predicted values were derived. The residual standard deviation was used to determine the $95 \%$ confidence limit for each prediction equation. Goodness of fit for each model was determined using the coefficient of determination $\left(\mathrm{r}^{2}\right)$.

\section{Results}

Table 2 illustrates the characteristics of the study population. The final study population comprised the 439 asymptomatic individuals with valid and reproducible data for oscillometry; 33 subjects were excluded since oscillometry data did not meet the predefined reproducibility criteria. This population was drawn from residents and persons employed in lower Manhattan and excludes rescue/recovery workers who may have been exposed occupationally to WTC dust for extended periods. The age for the male and female subjects ranged from 21 to 85 years. The distribution of heights within the male and female populations (supplementary material) include all but the tallest individuals ( $>2.03 \mathrm{~m}$ in men and $>1.83 \mathrm{~m}$ in women). The BMI range of the population was from 17 to $46 \mathrm{~kg} \cdot \mathrm{m}^{-2}$. The majority of the population had a college education, and the predominant racial/ethnic group was white non-Hispanic.

The spirometry pattern was characterised in each individual using published guidelines and lower limits of normal. Overall, $89 \%$ of the population had spirometry data that were within normal limits based on each individual's sex, age and height. There were low rates of obstruction (4\%) and low vital capacity (7\%) observed; since the lower limit of normal is defined by the 5th percentile, these data are compatible with expectations for a healthy population. 


\section{TABLE 2 Characteristics of study participants}

\begin{tabular}{|c|c|c|}
\hline & Male & Female \\
\hline Subjects" $\mathrm{n}(\%)$ & $223(51)$ & 216 (49) \\
\hline Age years & $46.7 \pm 11.2(21-85)$ & $46.0 \pm 11.9(21-76)$ \\
\hline Height m & $1.77 \pm 0.07(1.57-2.03)$ & $1.64 \pm 0.07(1.46-1.83)$ \\
\hline Weight kg & $83.1 \pm 17.1(51.3-170.0)$ & $63.9 \pm 12.7(43.1-147.4)$ \\
\hline BMI $\mathrm{kg} \cdot \mathrm{m}^{-2}$ & $26.5 \pm 4.7(17.2-44.9)$ & $23.8 \pm 4.4(16.8-46.6)$ \\
\hline \multicolumn{3}{|l|}{ Education \% } \\
\hline Unknown & 0 & 0.9 \\
\hline$<$ High school graduate & 1.3 & 2.8 \\
\hline High school graduate & 4.0 & 4.6 \\
\hline Some college & 8.5 & 10.7 \\
\hline$\geqslant$ College graduate & 86.0 & 81.1 \\
\hline \multicolumn{3}{|l|}{ Race \% } \\
\hline White non-Hispanic & 82.5 & 74.5 \\
\hline Black non-Hispanic & 3.6 & 8.3 \\
\hline Asian non-Hispanic & 10.3 & 14.8 \\
\hline Hispanic & 3.1 & 1.9 \\
\hline Other & $<1$ & $<1$ \\
\hline
\end{tabular}

Since all subjects were potentially exposed to dust from the collapse of the WTC, regression analyses were performed to assess whether there was a measureable effect of dust exposure on respiratory impedance. For this analysis, validated semi-quantitative measures of acute and chronic dust exposure were used [25, 26]. In all analyses, no significant relationship was observed between magnitude of dust exposure and oscillometry values in this asymptomatic population. Of note, the observed coefficients of determination $\left(\mathrm{r}^{2}\right)$ shown in table 3 were all $<0.02$, indicating that $<2 \%$ of the variance in oscillometry values was potentially explainable by exposure to WTC dust.

Table 4 illustrates the derived prediction equations for men and women. Models were successfully developed for a broad range of variables. All models demonstrated narrow residual standard deviation (RSD) as shown in table 4; the predicted values for selected parameters are displayed in figures 1 and 2 for male and female subjects at variable height but with normal body weight (i.e. $\mathrm{BMI}=25 \mathrm{~kg} \cdot \mathrm{m}^{-2}$ ). The effect of age on oscillometry parameters was minimal in both male and female subjects. Specifically, univariate correlation of age versus oscillometry variables demonstrated $r^{2}$ values that ranged from 0.0001 to 0.0260 . Consequently, age was significant in only one model ( $f_{\text {res }}$ in women) but explained $<1 \%$ of variation in $f_{\text {res }}$. Thus, to maintain consistency across all models, age coefficients were eliminated. Comparison of models that used height and BMI as independent predictors of oscillometry parameters to models that used height

TABLE 3 Coefficients of determination $\left(r^{2}\right)$ for relationship between oscillometry values and World Trade Center dust exposure

\begin{tabular}{|c|c|c|c|c|c|c|}
\hline & \multicolumn{2}{|c|}{ Acute exposures } & \multicolumn{4}{|c|}{ Chronic exposures } \\
\hline & $\begin{array}{l}\text { Dust cloud } \\
\text { density }\end{array}$ & $\begin{array}{l}\text { Time in dust } \\
\text { cloud }\end{array}$ & $\begin{array}{c}\text { Dust at } \\
\text { home/work }\end{array}$ & $\begin{array}{c}\text { Smoke at } \\
\text { home/work }\end{array}$ & $\begin{array}{c}\text { Time at } \\
\text { home/work }\end{array}$ & $\begin{array}{c}\text { Cleaning } \\
\text { home/work }\end{array}$ \\
\hline$R_{5}$ & 0.0003 & 0.0022 & 0.0004 & 0.0097 & 0.0146 & 0.0009 \\
\hline$R_{20}$ & $<0.0001$ & $<0.0001$ & $<0.0001$ & 0.0121 & 0.0160 & 0.0010 \\
\hline$R_{5-20}$ & 0.0021 & 0.0140 & 0.0028 & 0.0006 & 0.0022 & 0.0002 \\
\hline$x_{5}$ & 0.0004 & 0.0192 & 0.0013 & 0.0006 & 0.0017 & $<0.0001$ \\
\hline$A X$ & 0.0001 & 0.0141 & 0.0013 & 0.0038 & 0.0050 & 0.0009 \\
\hline$f_{\text {res }}$ & 0.0012 & 0.0070 & 0.0021 & 0.0003 & 0.0003 & 0.0011 \\
\hline
\end{tabular}

$R_{5}$ : resistance at an oscillating frequency of $5 \mathrm{~Hz} ; R_{20}$ : resistance at an oscillating frequency of $20 \mathrm{~Hz}$; $R_{5-20}$ : difference between resistance at 5 and $20 \mathrm{~Hz} ; X_{5}$ : reactance at an oscillating frequency of $5 \mathrm{~Hz}$; $A X$ : area under the reactance curve from $5 \mathrm{~Hz}$ to the resonant frequency; $f_{\text {res: }}$ resonant frequency. 


\begin{tabular}{|c|c|c|c|c|c|c|c|c|}
\hline & \multicolumn{4}{|c|}{ Male } & \multicolumn{4}{|c|}{ Female } \\
\hline & a & b & c & RSD & a & b & c & RSD \\
\hline \multicolumn{9}{|c|}{ Resistance } \\
\hline$R_{5}$ & 2.07069 & -1.05124 & 0.03337 & 0.24603 & 2.22395 & -0.98351 & 0.02903 & 0.24652 \\
\hline$R_{10}$ & 2.00342 & -1.02184 & 0.03219 & 0.24212 & 2.15420 & -0.95864 & 0.02737 & 0.24568 \\
\hline$R_{15}$ & 1.92723 & -0.91154 & 0.02674 & 0.23324 & 2.05048 & -0.85489 & 0.02451 & 0.23813 \\
\hline$R_{20}$ & 1.95570 & -0.81148 & 0.02042 & 0.22300 & 2.01077 & -0.72768 & 0.02009 & 0.22939 \\
\hline$R_{5-15}$ & 0.51755 & -0.51198 & 0.02192 & 0.19274 & 0.59340 & -0.53125 & 0.02103 & 0.19460 \\
\hline$R_{5-20}$ & 0.37755 & -0.70125 & 0.03588 & 0.28254 & 0.59582 & -0.91438 & 0.03737 & 0.36151 \\
\hline \multicolumn{9}{|c|}{ Reactance } \\
\hline$x_{5}$ & 0.10509 & 0.82626 & -0.01775 & 0.241371 & 0.29066 & 0.73387 & -0.01984 & 0.17914 \\
\hline$x_{10}$ & 1.14127 & 0.29830 & -0.01128 & 0.121614 & 1.07282 & 0.34050 & -0.01080 & 0.09940 \\
\hline$A X$ & 4.36142 & -3.47450 & 0.08784 & 0.687626 & 4.67153 & -3.31633 & 0.06719 & 0.69309 \\
\hline$f_{\text {res }}$ & 2.72388 & -0.69422 & 0.03115 & 0.251555 & 3.30330 & -0.95364 & 0.02520 & 0.26591 \\
\hline \multicolumn{9}{|c|}{$\begin{array}{l}\text { Lnloscillometry parameter }=\mathrm{a}+\mathrm{b} \times \text { height }+\mathrm{c} \times \text { body mass index. For } R_{5-15} \text { and } R_{5-20} \text { the equation yields the } \\
\text { predicted value }+1 ; \text { for } X_{5} \text { and } X_{10} \text { the equation yields the predicted value }+4 \text {. Units: height }(\mathrm{m}) ; \text { body mass } \\
\text { index }\left(\mathrm{kg} \cdot \mathrm{m}^{-2}\right) \text {. RSD: residual standard deviation; } R_{5} \text { : resistance at an oscillating frequency of } 5 \mathrm{~Hz} \text {; } \\
R_{10} \text { : resistance at an oscillating frequency of } 10 \mathrm{~Hz} ; R_{15} \text { : resistance at an oscillating frequency of } 15 \mathrm{~Hz} \text {; } \\
R_{20} \text { : resistance at an oscillating frequency of } 20 \mathrm{~Hz} ; R_{5-15} \text { : difference between resistance at } 5 \mathrm{and} 15 \mathrm{~Hz} \text {; } \\
R_{5-20} \text { : difference between resistance at } 5 \text { and } 20 \mathrm{~Hz} ; X_{5} \text { : reactance at an oscillating frequency of } 5 \mathrm{~Hz} ; \\
X_{10} \text { : reactance at an oscillating frequency of } 10 \mathrm{~Hz} ; A X \text { : area under the reactance curve from } 5 \mathrm{~Hz} \text { to the } \\
\text { resonant frequency; } f_{\text {res: }} \text { resonant frequency. }\end{array}$} \\
\hline
\end{tabular}

and weight demonstrated nearly identical predicted values. However, the final models chosen were BMI-based since the correlation coefficients were always larger than the corresponding correlation coefficients for weight-based models. Specifically, the $\mathrm{r}^{2}$ values for BMI and height-based models improved by an average of $5.8 \pm 3.9 \%$ in male subjects and $1.8 \pm 2.8 \%$ in female subjects as compared with the $\mathrm{r}^{2}$ values for weight- and height-based models.

Figures 1 and 2 also graphically display the present prediction equations and confidence intervals (black lines and shaded area) on a background of data derived from prior publications (coloured lines) [11, 13, 14]. Selected parameters are displayed for male and female subjects at variable height but with normal body weight (i.e. $\mathrm{BMI}=25 \mathrm{~kg} \cdot \mathrm{m}^{-2}$ ). To ensure comparability with the current data, prior studies were limited to investigations that also used an IOS device in patients over a similar age range. Note, not all studies derived normative equations for $R_{5-20}$ and $f_{\text {res }}$ and are therefore not included in the relevant graphs. The normative data derived in the present study align well with prior publications. While there are differences visible across studies, the confidence intervals for the data from the present study overlap with those derived in the prior studies.

Figures 3 and 4 show the effect of body size, as assessed by BMI, on respiratory impedance. Predicted values for oscillometry parameters are shown as a function of height across a range of BMI that matches the range of body sizes for the subjects included in this study (BMI isopleths from 20 to $45 \mathrm{~kg} \cdot \mathrm{m}^{-2}$ ). The effect of BMI is readily visible; with increasing BMI at any given height, there is a nonlinear increase in resistance and reactance that is exaggerated as the chest wall, lung and airway becomes increasingly compressed from mass loading.

\section{Discussion}

The present study capitalises on an existing dataset in a well characterised healthy and asymptomatic urban population to derive normative prediction equations for respiratory impedance using the commercially available IOS device. Study results were notable for: 1) successful derivation of normative prediction equations with narrow confidence intervals for a broad range of respiratory oscillometry parameters in a healthy asymptomatic urban population; 2) demonstration of values for respiratory impedance that were similar to other published healthy populations despite numerous environmental exposures, including exposure to WTC dust; and 3) utilisation of the normative equations to demonstrate the effect of obesity on respiratory impedance.

The present study compared the derived prediction equations with prior publications $[11,13,14]$. Since concern has been raised that different oscillometry devices might yield different data in a given individual 
Male subjects
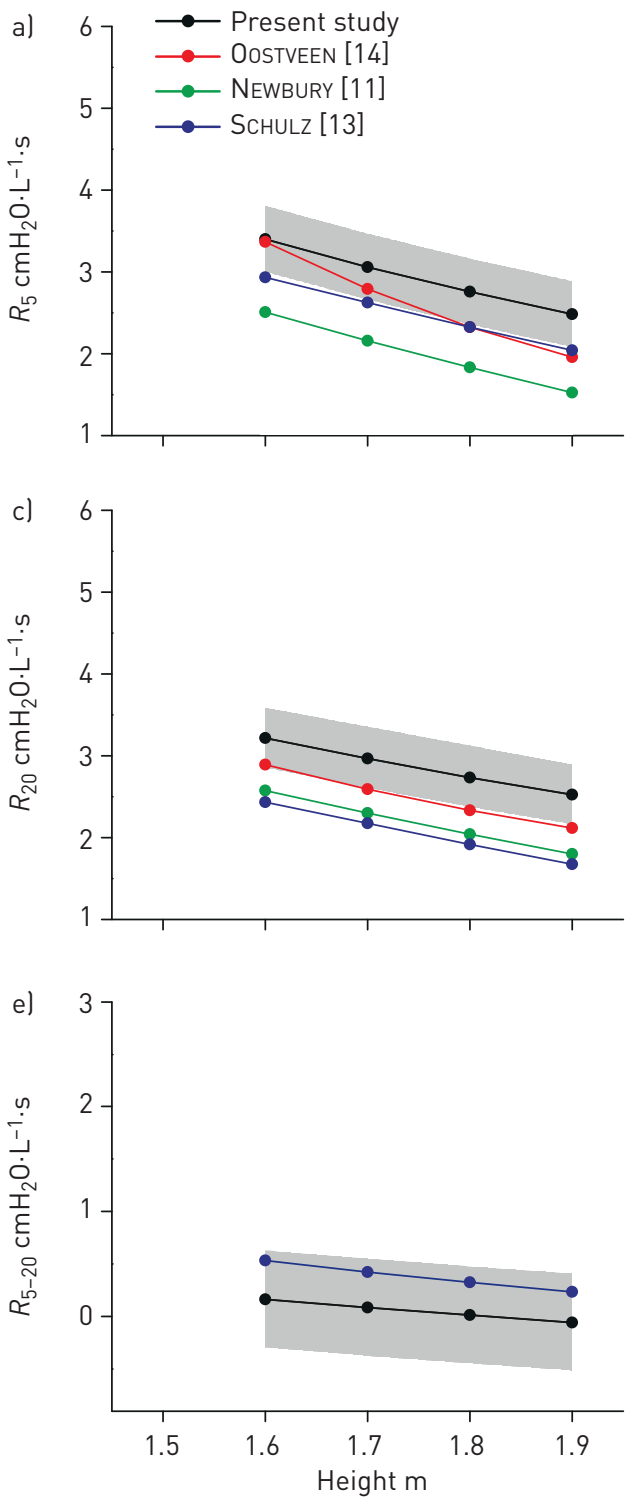

Female subjects

b)

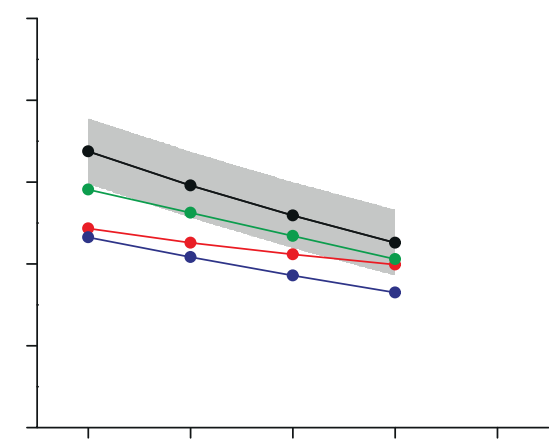

d)

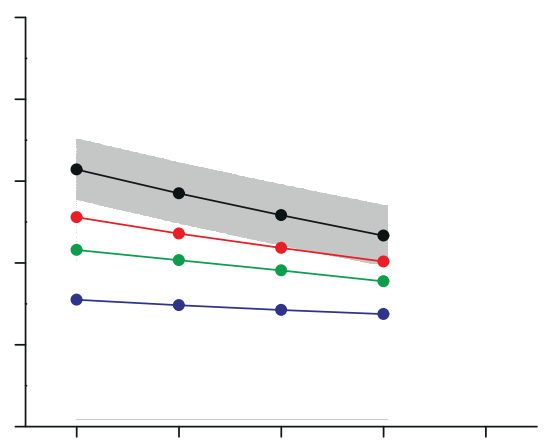

f)

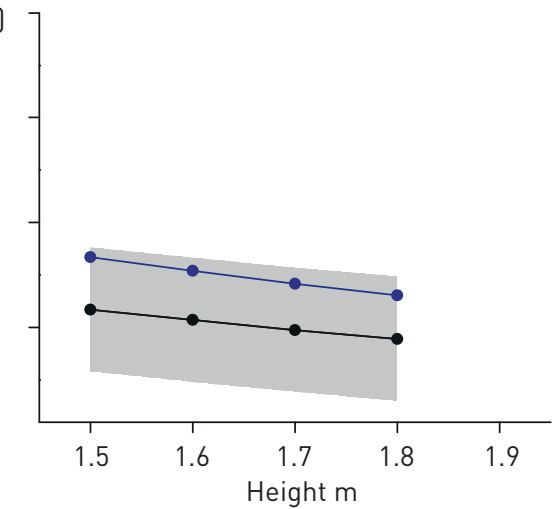

FIGURE 1 Predicted values for selected oscillometry resistance parameters are graphed as a function of height. The derived data were obtained at a constant body mass index of $25 \mathrm{~kg} \cdot \mathrm{m}^{-2}$. The black lines and shaded areas depict the predicted values and the $95 \%$ confidence interval for each parameter derived in the present study. The coloured lines depict predicted values computed based on other published normative data studies $[11,13,14]$. The left column of graphs shows data for male subjects and the right column shows similar graphs for female subjects. $R_{5}$ : resistance at an oscillating frequency of $5 \mathrm{~Hz} ; R_{20}$ : resistance at an oscillating frequency of $20 \mathrm{~Hz} ; R_{5-20}$ : difference between resistance at 5 and $20 \mathrm{~Hz}$.

[14-17], this analysis was limited to studies that used the IOS device, and other commercial or proprietary equipment were excluded. The observed normative data in the present study compared favourably across a broad range of parameters and body sizes.

To account for differences in body size across healthy subjects, lung function is traditionally modelled as a function of height and weight; however, body size is clinically assessed by proportionality of weight to height (i.e. BMI). The present study derived normative data models using height and weight as independent predictors and compared them to models that used height and BMI. OosTVEen et al. [14] demonstrated that BMI-based predicted equations were not superior to weight-based equations. In contrast, in the present study, the BMI-based models fit our population data with either equivalent or better fit than weight-based equations (i.e. higher $r^{2}$ values). This observation is in accord with the concept that height is an independent predictor of respiratory function as it relates to thoracic cage and lung size, 
Male subjects
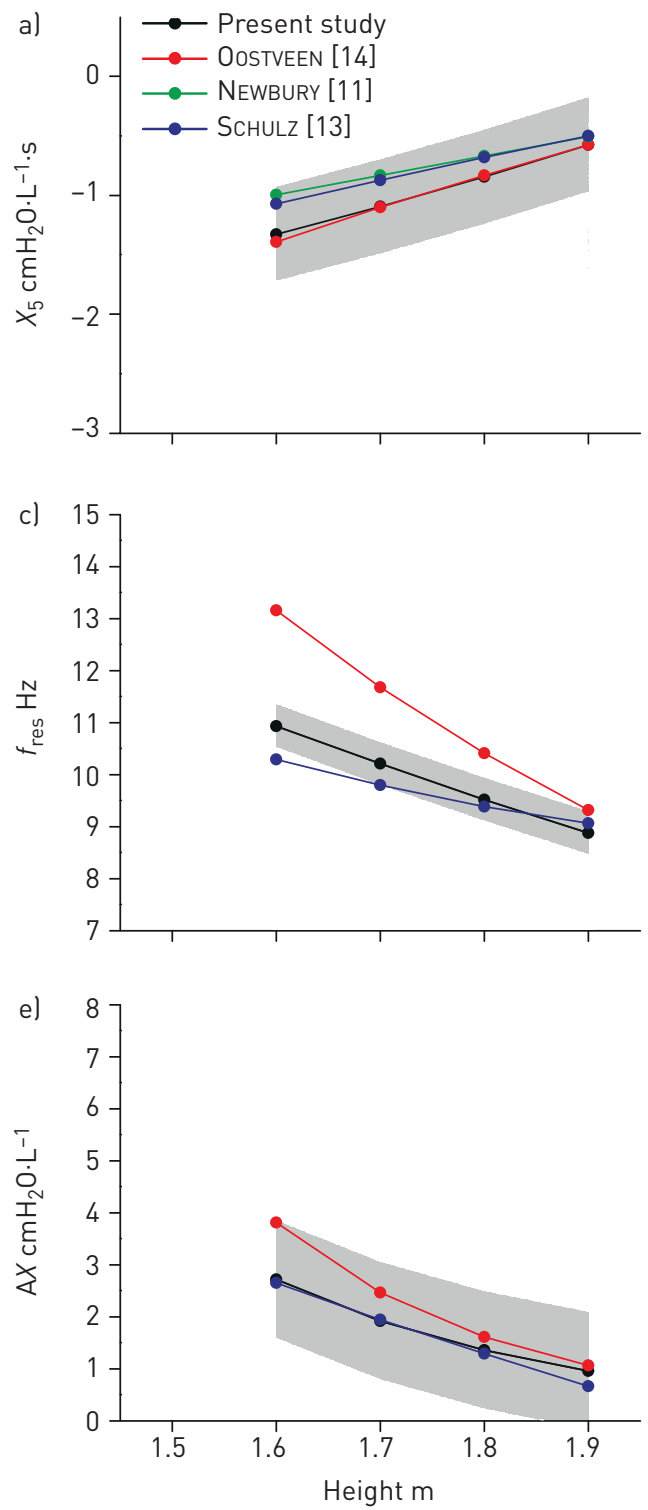

Female subjects

b)

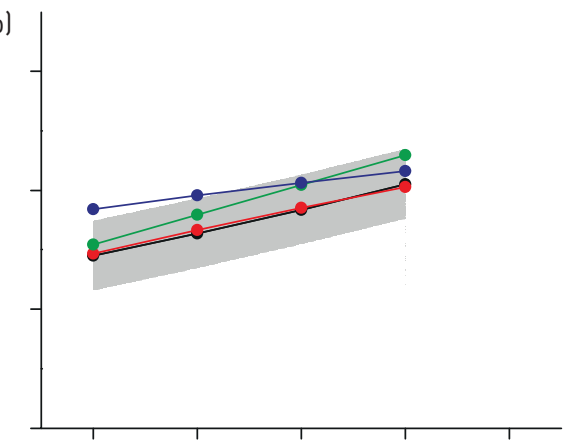

d)

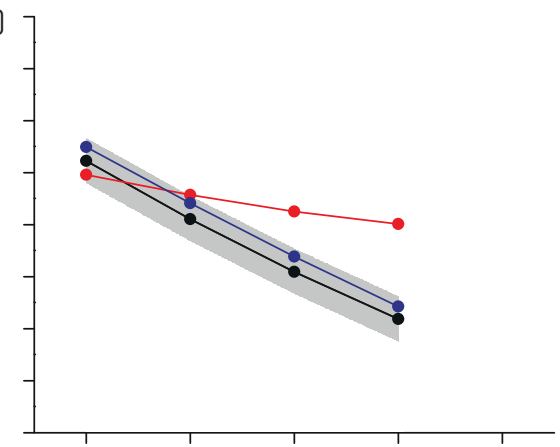

f)

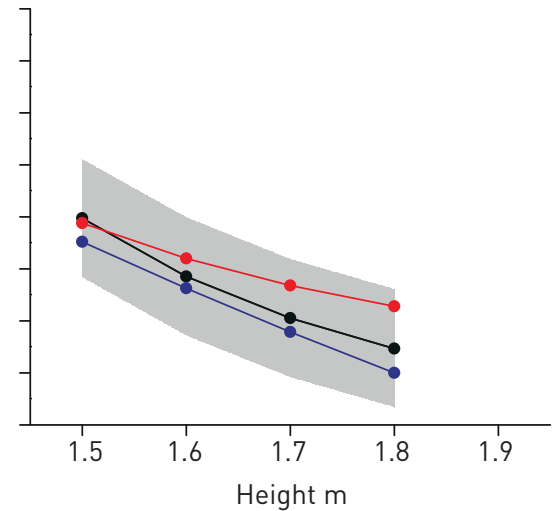

FIGURE 2 Predicted values for selected oscillometry reactance parameters are graphed as a function of height. The derived data were obtained at a constant body mass index of $25 \mathrm{~kg} \cdot \mathrm{m}^{-2}$. The black lines and shaded areas depict the predicted values and the $95 \%$ confidence interval for each parameter derived in the present study. The coloured lines depict predicted values computed based on other published normative data studies $[11,13,14]$. The left column of graphs shows data for male subjects and the right column shows similar graphs for female subjects. $X_{5}$ : reactance at an oscillating frequency of $5 \mathrm{~Hz} ; A X$ : area under the reactance curve from $5 \mathrm{~Hz}$ to the resonant frequency; $f_{\text {res }}$ : resonant frequency.

while BMI adds the independent contribution of excess body weight on chest wall, lung and airway compression. This approach could be beneficial compared with use of weight as an independent predictor since a given weight has markedly different effects as height varies (e.g. at constant weight, BMI would increase as height falls). Accordingly, data from ZERAH et al. [19] and AlbuQUerQue et al. [24] demonstrate an exaggerated effect of obesity on respiratory impedance as BMI exceeds $40 \mathrm{~kg} \cdot \mathrm{m}^{-2}$, a threshold with insufficient subject numbers to evaluate either in the present study or in the data of OosTVEen et al. [14]. Thus, current and prior equations may not be applicable to individuals with body size that exceeds the respective study populations.

One surprising finding in the present study is the lack of significance of subject age as a predictor of respiratory impedance, which contrasts with other normative data studies [10-14]. In the present study the age coefficients were relatively small compared with the height and BMI coefficients and only achieved 

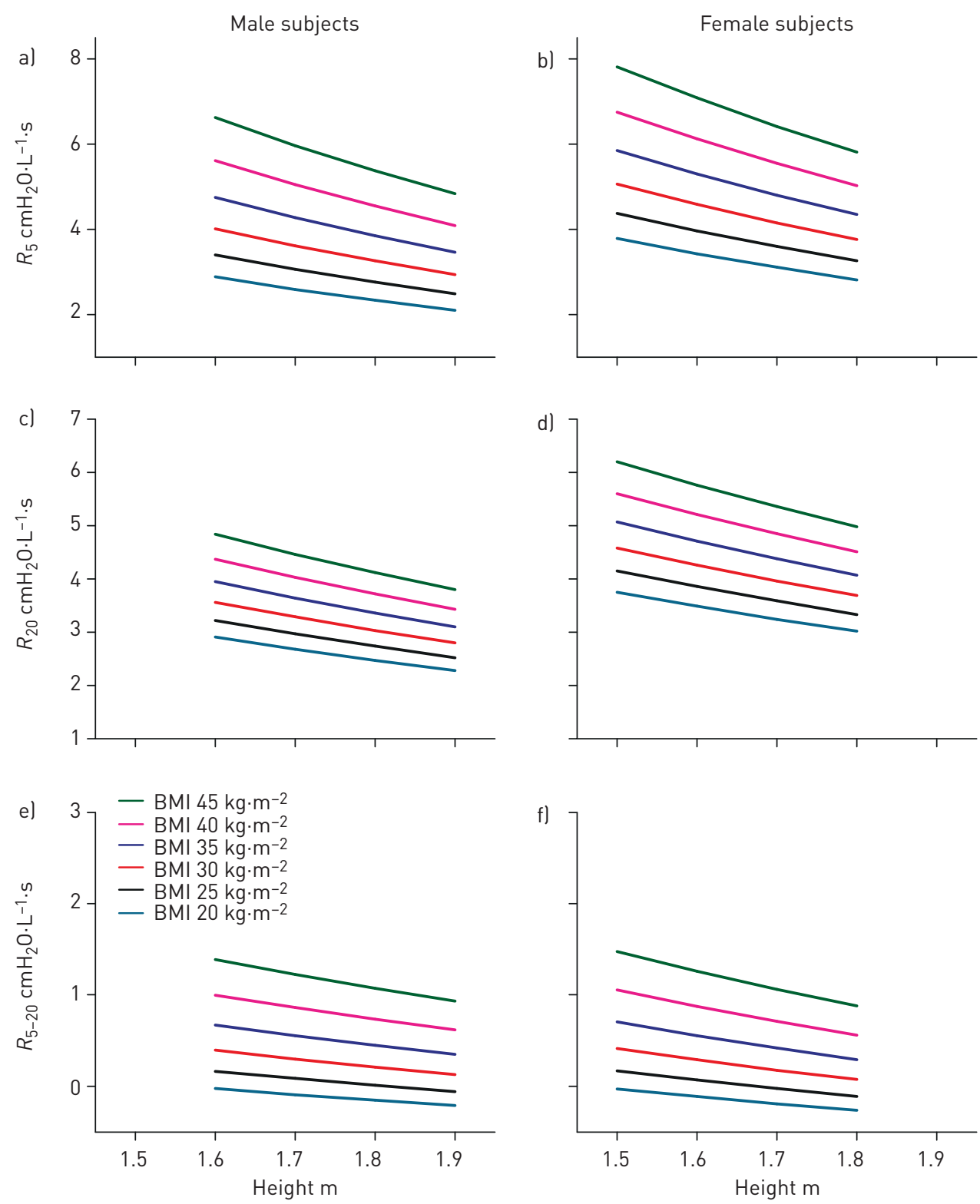

FIGURE 3 Predicted values for selected oscillometry resistance parameters are graphed as a function of height. The lines display predicted values for isopleths of body mass index ranging from 20 to $45 \mathrm{~kg} \cdot \mathrm{m}^{-2}$. The left column of graphs shows data for male subjects and the right column shows similar graphs for female subjects. $R_{5}$ : resistance at an oscillating frequency of $5 \mathrm{~Hz} ; R_{20}$ : resistance at an oscillating frequency of $20 \mathrm{~Hz} ; R_{5-20}$ : difference between resistance at 5 and $20 \mathrm{~Hz}$.

statistical significance in one model. Specifically, for $f_{\text {res }}$ in females the age coefficient was one to two orders of magnitude smaller than the height and the BMI coefficients. Consequently, inclusion of age changed the predicted values of $f_{\text {res }}$ to a minimal degree and it was omitted from the final models. Similar findings occurred in the study of OOstveEN et al. [14], which has a normative dataset that is similar in size to the dataset in the present study. In the Oostveen study, the age coefficients were also very small as compared with height and weight coefficients, and age was not a significant predictor for multiple oscillometry parameters. These observations suggest that age has a relatively small effect on respiratory mechanics during tidal breathing in contrast to forced exhalation or assessment of lung volumes where chest wall mechanics and muscle strength become relevant.

The population used in the present study was exposed to dust from the WTC collapse with potential for inhalational lung injury. The validity of using this population to derive normative equations needs to be considered especially since abnormal large and small airway function has been documented in numerous WTC dust-exposed populations [25, 32-34]. It should be noted that a prior epidemiological case-control 

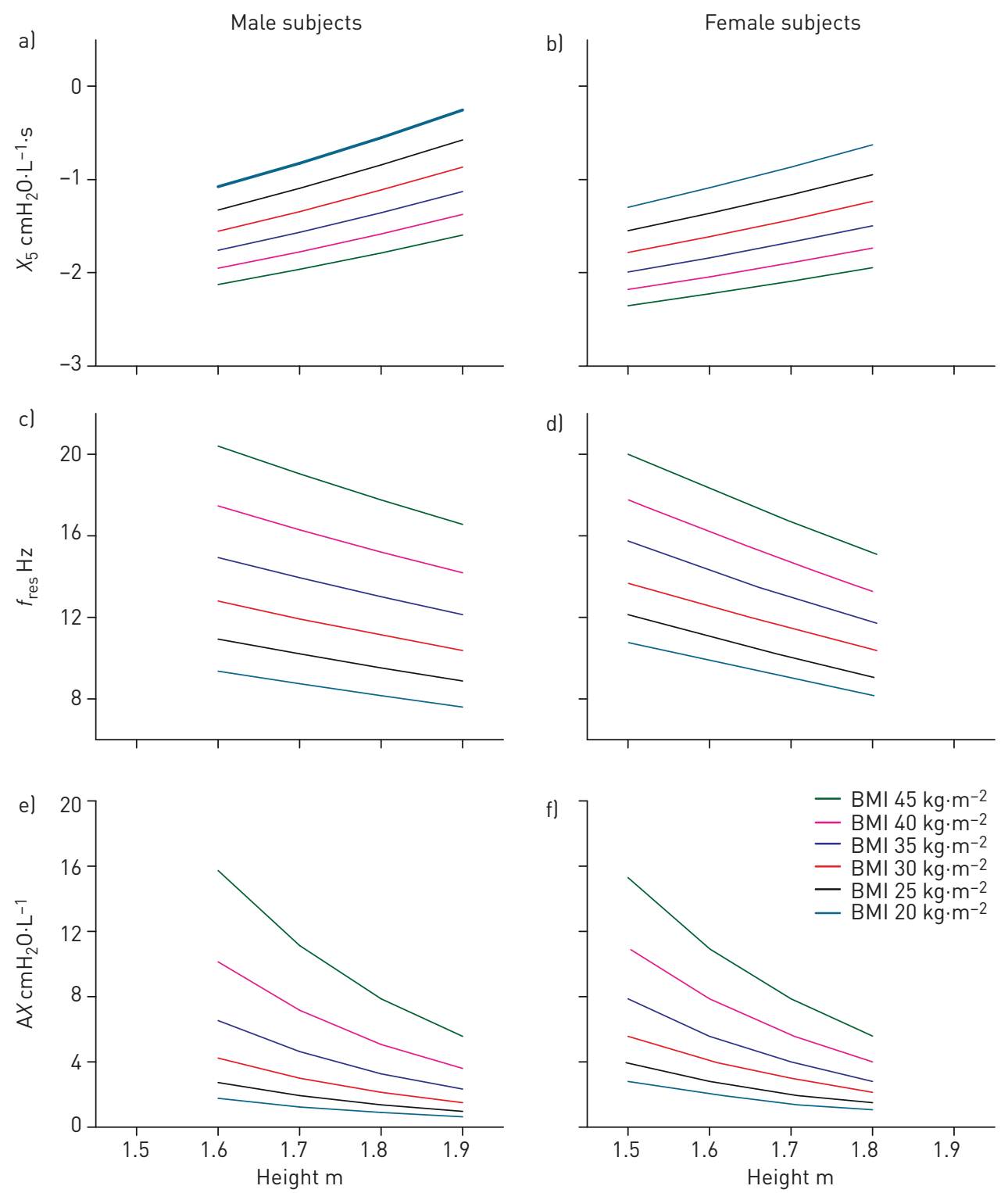

FIGURE 4 Predicted values for selected oscillometry reactance parameters are graphed as a function of height. The lines display predicted values for isopleths of body mass index ranging from 20 to $45 \mathrm{~kg} \cdot \mathrm{m}^{-2}$. The left column of graphs shows data for male subjects and the right column shows similar graphs for female subjects. $X_{5}$ : reactance at an oscillating frequency of $5 \mathrm{~Hz}$; $A X$ : area under the reactance curve from $5 \mathrm{~Hz}$ to the resonant frequency; $f_{\text {res }}$ : resonant frequency.

study demonstrated that airway dysfunction was only evident in individuals with new onset and persistent lower respiratory symptoms, a finding that was absent in the population used in the present study [25]. Moreover, absence of symptoms was confirmed on numerous longitudinal surveys conducted over 7 years post-September 11, 2001 and before the present data were collected. Nevertheless, to address this potential confounder, a validated assessment of WTC dust exposure magnitude was regressed against observed respiratory oscillometry values, and no correlation was observed. Of importance, the correlation coefficients for these analyses were nearly zero excluding the potential for trends that did not reach statistical significance. Lastly, the observed oscillometry values were similar to prior published normative data, further supporting the respiratory health of this urban cohort [10-14].

There are several characteristics of the present study that deserve comment. Use of data previously collected in a case-control study provided an opportunity to analyse data in a robust healthy urban population. One unique feature is availability of longitudinal data prior to the present study (and after WTC dust exposure) to confirm absence of respiratory symptoms, physician diagnosis of respiratory disease and use of respiratory medications documented at numerous time points. In addition, data were 
collected with strict and blinded quality control that ensured reproducible trials without evidence of artefact and/or glottis closure. A strict definition was used to include only lifetime nonsmokers $(<5$ packs per lifetime) in the study. Although there was only a limited number of subjects with age $>65$, the age coefficients have generally been non-significant or the observed slopes are of minor magnitude. Lastly while there was potential for WTC dust exposure, oscillometry values were not related to exposure magnitude and were similar to prior studies in variable populations [10-14] reinforcing the validity of using our population to derive normative prediction equation for respiratory impedance.

In summary, the present study evaluates a large cohort of healthy urban subjects assessed with an IOS device. Prediction equations were derived from this population with repeated absence of symptoms that should facilitate application of the IOS device in the clinical setting. In addition, the data suggest that modelling the effect of body size on lung mechanics may be best performed using height and BMI as independent variables rather than the traditional approach of using height and weight (which does not account for the proportionality between height and weight in a given individual). This approach is based on the concept that height is an independent predictor of respiratory function as it relates to lung size, while BMI adds the independent contribution of excess body weight on respiratory system mechanics. Lastly, the observation that urban exposures may have minimal effect on respiratory impedance may allow application of these normative prediction equations to a range of clinical populations.

Data availability: Data sharing is available by request from the World Trade Center Health Registry at the New York City Department of Health and Mental Hygiene.

Conflict of interest: K.I. Berger reports grants from CDC/NIOSH during the conduct of the study. M. Wohlleber has nothing to disclose. R.M. Goldring has nothing to disclose. J. Reibman has received funding as a consultant for AstraZeneca, Genentech and Novartis. She has also been a recipient of grant and contract funding from the Centers of Disease Control/NIOSH. M.R. Farfel has nothing to disclose. S.M. Friedman reports grants from CDC/NIOSH during the conduct of the study. B.W. Oppenheimer has nothing to disclose. S.D. Stellman has nothing to disclose. J.E. Cone reports grants from NIOSH CDC during the conduct of the study. Y. Shao reports grants from the National Institute of Occupational Safety and Health, and the National Institute of Environmental Health Science, during the conduct of the study.

Support statement: This study was supported by National Institute of Environmental Health Sciences grant P30ES00260, National Institute for Occupational Safety and Health grant U50 OH009739, Agency for Toxic Substances and Disease Registry grant U50/ATU272750, and Centers for Disease Control and Prevention grants 200-2011-39413, 200-2017-93327 and 200-2017-93427. Funding information for this article has been deposited with the Crossref Funder Registry.

\section{References}

1 King GG. Cutting edge technologies in respiratory research: lung function testing. Respirology 2011; 16: 883-890.

2 Pasker HG, Schepers R, Clement J, et al. Total respiratory impedance measured by means of the forced oscillation technique in subjects with and without respiratory complaints. Eur Respir J 1996; 9: 131-139.

3 Bickel S, Popler J, Lesnick B, et al. Impulse oscillometry: interpretation and practical applications. Chest 2014; 146: 841-847.

4 Berger KI, Goldring RM, Oppenheimer BW. POINT: should oscillometry be used to screen for airway disease? Yes. Chest 2015; 148: 1131-1135.

5 Clement J, Landser FJ, Van de Woestijne KP. Total resistance and reactance in patients with respiratory complaints with and without airways obstruction. Chest 1983; 83: 215-220.

6 Kaminsky DA. What does airway resistance tell us about lung function? Respir Care 2012; 57: 85-96.

7 Knudson RJ, Lebowitz MD, Holberg CJ, et al. Changes in the normal maximal expiratory flow-volume curve with growth and aging. Am Rev Respir Dis 1983; 127: 725-734.

8 Hankinson JL, Odencrantz JR, Fedan KB. Spirometric reference values from a sample of the general U.S population. Am J Respir Crit Care Med 1999; 159: 179-187.

9 Quanjer PH, Stanojevic S, Cole TJ, et al. Multi-ethnic reference values for spirometry for the 3-95-yr age range: the global lung function 2012 equations. Eur Respir J 2012; 40: 1324-1343.

10 Shiota S, Katoh M, Fujii M, et al. Predictive equations and the reliability of the impulse oscillatory system in Japanese adult subjects. Respirology 2005; 10: 310-315.

11 Newbury W, Crockett A, Newbury J. A pilot study to evaluate Australian predictive equations for the impulse oscillometry system. Respirology 2008; 13: 1070-1075.

12 Aarli BB, Eagan TM, Ellingsen I, et al. Reference values for within-breath pulmonary impedance parameters in asymptomatic elderly. Clin Respir J 2013; 7: 245-252.

13 Schulz H, Flexeder C, Behr J, et al. Reference values of impulse oscillometric lung function indices in adults of advanced age. PLoS One 2013; 8: e63366.

14 Oostveen E, Boda K, van der Grinten CP, et al. Respiratory impedance in healthy subjects: baseline values and bronchodilator response. Eur Respir J 2013; 42: 1513-1523.

15 Zimmermann SC, Watts JC, Bertolin A, et al. Discrepancy between in vivo and in vitro comparisons of forced oscillation devices. J Clin Monit Comput 2018; 32: 509-512.

16 Hellinckx J, Cauberghs M, De Boeck K, et al. Evaluation of impulse oscillation system: comparison with forced oscillation technique and body plethysmography. Eur Respir J 2001; 18: 564-570.

17 Dandurand RJ, Lavoie JP, Lands LC, et al. Comparison of oscillometry devices using active mechanical test loads. ERJ Open Res 2019; 5: 00160-2019. 
Oppenheimer BW, Berger KI, Segal LN, et al. Airway dysfunction in obesity: response to voluntary restoration of end expiratory lung volume. PLoS One 2014; 9: e88015.

19 Zerah F, Harf A, Perlemuter L, et al. Effects of obesity on respiratory resistance. Chest 1993; 103: 1470-1476.

20 Salome CM, King GG, Berend N. Physiology of obesity and effects on lung function. J Appl Physiol (1985) 2010; 108: 206-211.

21 Oppenheimer BW, Macht R, Goldring RM, et al. Distal airway dysfunction in obese subjects corrects after bariatric surgery. Surg Obes Relat Dis 2012; 8: 582-589.

22 Al-Alwan A, Bates JH, Chapman DG, et al. The nonallergic asthma of obesity. A matter of distal lung compliance. Am J Respir Crit Care Med 2014; 189: 1494-1502.

23 Peters U, Hernandez P, Dechman G, et al. Early detection of changes in lung mechanics with oscillometry following bariatric surgery in severe obesity. Appl Physiol Nutr Metab 2016; 41: 538-547.

24 Albuquerque CG, Andrade FM, Rocha MA, et al. Determining respiratory system resistance and reactance by impulse oscillometry in obese individuals. J Bras Pneumol 2015; 41: 422-426.

25 Friedman SM, Maslow CB, Reibman J, et al. Case-control study of lung function in World Trade Center Health Registry area residents and workers. Am J Respir Crit Care Med 2011; 184: 582-589.

26 Maslow CB, Friedman SM, Pillai PS, et al. Chronic and acute exposures to the World Trade Center disaster and lower respiratory symptoms: area residents and workers. Am J Public Health 2012; 102: 1186-1194.

27 Miller MR, Hankinson J, Brusasco V, et al. Standardisation of spirometry. Eur Respir J 2005; 26: 319-338.

28 Graham BL, Steenbruggen I, Miller MR, et al. Standardization of Spirometry 2019 Update. An Official American Thoracic Society and European Respiratory Society Technical Statement. Am J Respir Crit Care Med 2019; 200: e70-e88.

29 Hankinson JL, Kawut SM, Shahar E, et al. Performance of American Thoracic Society-recommended spirometry reference values in a multiethnic sample of adults: the multi-ethnic study of atherosclerosis (MESA) lung study. Chest 2010; 137: 138-145.

30 Oostveen E, MacLeod D, Lorino H, et al. The forced oscillation technique in clinical practice: methodology, recommendations and future developments. Eur Respir J 2003; 22: 1026-1041.

31 King GG, Bates J, Berger KI, et al. Technical standards for respiratory oscillometry. Eur Respir J 2020; 55: 1900753.

32 Oppenheimer BW, Goldring RM, Herberg ME, et al. Distal airway function in symptomatic subjects with normal spirometry following World Trade Center dust exposure. Chest 2007; 132: 1275-1282.

33 Prezant DJ, Weiden M, Banauch GI, et al. Cough and bronchial responsiveness in firefighters at the World Trade Center site. N Engl J Med 2002; 347: 806-815.

34 Berger KI, Turetz M, Liu M, et al. Oscillometry complements spirometry in evaluation of subjects following toxic inhalation. ERJ Open Res 2015; 1: 00043-2015. 